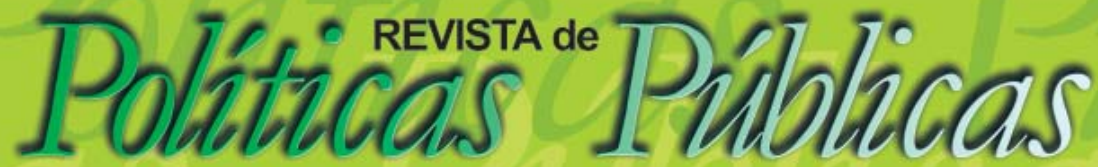

\section{CONFLITOS SOCIOAMBIENTAIS E A AMEAÇA AO PROCESSO DE DEMARCAÇÃO DE TERRAS QUILOMBOLAS NO BRASIL}

Iris Pontes Soares ${ }^{1}$

\section{Resumo}

O objetivo do presente artigo é refletir acerca dos conflitos socioambientais e sua relação com os processos de demarcação de terras quilombolas no Brasil. Pretende, ademais, apontar que o avanço do agronegócio e da mecanização do campo vêm aumentando os conflitos que envolvem os processos de demarcação restringindo o acesso à terra pelas comunidades quilombolas e, em muitos casos, impossibilitando a manutenção de suas formas de vida e produção. Para tanto, o artigo em questão, fruto dos processos de preparação de dissertação em serviço social, realiza pesquisa bibliográfica e documental.

Palavras-chave: Conflitos socioambientais, populações quilombolas, demarcação de terras.

\section{SOCIO-ENVIRONMENTAL CONFLICTS AND THE THREAT TO THE DEMARCATION PROCESS OF QUILOMBOLA LANDS IN BRAZIL}

\begin{abstract}
The purpose of this article is to initiate the debate about the socio-environmental conflicts and their relations with the processes of demarcation of quilombola lands in Brazil. It is the intended to point that the advancement of agribusiness and the mechanization of the field have increased the conflicts that surround the

1 Assistente Social, Mestranda em Serviço Social pela Universidade Federal de Pernambuco (UFPE). E-mail: irispontessoares@yahoo.com.br/ Endereço: Universidade Federal de Pernambuco - UFPE: Av. Prof. Moraes Rego, 1235 - Cidade Universitária, Recife - PE. CEP: 50670-901.
\end{abstract}


demarcation processes, restricting access to land by the quilombola communities and in many cases making it impossible to maintain their forms of life and production. For the realization of the article in question, result of the processes of preparation of dissertation in social service, bibliographical and documentary research was carried out.

Key words: Socio-environmental conflicts, quilombola populations, demarcation of lands.

\section{INTRODUÇÃO}

Historicamente a população do campo teve seus direitos de acesso à terra e às políticas públicas negligenciados. O Brasil tem como herança uma estrutura fundiária escravocrata, repleta de latifúndios, que manifesta a concentração de poder econômico e político em torno dos grandes proprietários de terras, a burguesia rural. Já à população do campo foi destinada uma série de condições precárias de vida no que se refere, principalmente, a esse acesso desigual. À negritude, foi direcionada a face mais perversa desse processo, já que a ela foi negada, salvo raras exceções desde sua chegada ao Brasil, o uso da terra e principalmente a garantia de sua propriedade.

Com a abolição da escravatura em 1888 e a inserção do trabalho livre assalariado no Brasil, a população negra nascida livre ou recém-liberta foi inserida nessa nova forma de organização do trabalho a partir das diferenças entre as regiões brasileiras. Aos que se localizavam em territórios onde ainda existiam terras sem cultivo, os recém-libertos se dedicaram à agricultura de subsistência, inserindo-se de maneira restrita na atividade assalariada. No entanto, essa foi uma experiência rara. Na maior parte dos casos, os antigos escravos foram incorporados ao trabalho livre. No Nordeste as mudanças foram principalmente de natureza geográfica, na qual os recém-libertos foram inseridos como força de trabalho em engenhos distintos dos anteriores. Inexistiam terras livres para o cultivo e as atividades nos centros urbanos eram restritas. (GORENDER, 2016a).

No Sudeste, em especial em São Paulo, apesar de existirem negros ou ex-escravos nos empregos industriais, estes foram majoritariamente incorporados nas atividades mal remuneradas, em especial do serviço doméstico, ao mesmo tempo em que passaram a conviver com o desemprego, trabalho informal e precário. (MARTINS, 2016). Nessa região, houve um grande incentivo à vinda de imigrantes. Essa escolha tinha como um de seus fundamentos o re- 
forço da ideologia racista. Teses de inaptidão ao trabalho livre ou a dita impossibilidade de disputa com o colono europeu branco fortaleceu esse processo, que tinha como um dos objetivos embranquecer a população da região. Somado a isso, a imigração garantiu também a formação de um exército industrial de reserva e impôs à população negra brasileira, de acordo com Gorender (2016a), uma reserva da reserva. "Classificar as pessoas segundo a cor tem sido vantajoso ao funcionamento do capitalismo, pois mantém a reserva de segunda linha dos discriminados, sempre disponível para o trabalho em troca de salários rebaixados". (GORENDER, 2016a, p. 223).

Com isso é possível aferir que essa população foi afastada dos espaços rurais e os que neles permaneceram continuam disputando com os setores dominantes do campo o acesso ao território. Essa discrepância entre esses segmentos de classes gera e intensifica a desigualdade social no campo e os conflitos em torno da disputa por terras no país.

Os conflitos agrários são parte constitutiva da formação social brasileira e se expressam desde a colonização. No entanto, o reposicionamento do Brasil na Divisão Internacional do Trabalho como um grande fornecedor de commodities, na virada do século XX para o XXI, ocasionou uma meia volta no processo de industrialização, o qual teve no pós-guerra seu maior impulso. Esse processo vem gerando fortes impactos ao campo. Esses se evidenciam nos avanços do capital na área rural e a consequente complexificação da vida do camponês, principalmente com o desenvolvimento do agronegócio ${ }^{1}$, de forma que a questão não se restringe ao acesso e propriedade da terra, à ausência ou insuficiência dos programas de extensão rural, mas se estendem à poluição crescente do ar, das águas e do solo, à apropriação privada dos recursos naturais e à retirada forçosa de bens de uso comum.

A expansão do agronegócio no campo promove, assim, contraditória e dialeticamente, a ampliação das pautas dos movimentos campesinos. As lutas pela terra e por políticas públicas de apoio à produção rural permanecem existindo, mas a elas são somadas as mobilizações contra a destrutividade ambiental produzida pelo avanço do agronegócio, o direito de plantar e reproduzir as sementes originárias (crioulas); também se opera o entrecruzamento com a luta pelo reconhecimento dos povos ancestrais e seus descendentes como destinatários de políticas específicas, como é o caso dos 
quilombolas. Nesse aspecto, reside a importância da demarcação de terras no contexto dessa pauta ampliada, denominada por alguns autores de conflitos socioambientais.

O debate dos conflitos socioambientais vem se intensificando em diversas áreas do conhecimento e se tornando uma discussão de domínio público. Em um estudo realizado no ano de 2014, a Universidade Autônoma de Barcelona mapeou os conflitos em todo o mundo e o Brasil apareceu como o terceiro país a sediá-los. (MAPA..., 2014). Segundo a mesma pesquisa, vários destes conflitos estão relacionados à expansão da agricultura, à mineração, além dos conflitos gerados pelas obras de infraestrutura e geração de energia, como: estradas, ferrovias, oleodutos, complexos portuários, hidroelétricas e termelétricas. $\mathrm{O}$ referido estudo destaca, ainda, que as comunidades tradicionais, os pescadores artesanais, os povos indígenas e quilombolas permanecem distantes da participação do sistema político e assumem os riscos e danos do pretenso desenvolvimento.

Observa-se, assim, que o debate sobre os conflitos socioambientais vem se tornando cada vez mais expressivo na sociedade e se constitui, também, como um campo de intervenção do Serviço Social. Essa realidade serve tanto para pensar a intervenção profissional, como também para formular sobre os impactos ao meio ambiente e às populações tradicionais.

No atual cenário econômico e político brasileiro constata-se uma expansão de setores que representam interesses conservadores nos espaços políticos nacionais. Essa situação se agravou com o golpe parlamentar-judiciário-midiático de 2016 e a radicalização da perspectiva neoliberal onde são acirrados os processos de intensificação das possibilidades de perdas de direitos conquistados anteriormente. $\mathrm{O}$ avanço conservador vem atingindo diversos segmentos da classe trabalhadora e, a população do campo, certamente, vem sendo impactada.

Os setores conservadores e que encabeçam os interesses da burguesia rural vêm ganhando mais notoriedade e domínio, inclusive, sobre a esfera pública. Um importante indicador nesse sentido é o sucessivo aumento da bancada ruralista do Congresso Nacional. Esse movimento que já se manifestava desde as eleições de 2004, no atual momento avança. No ano em questão a bancada tinha 154 representantes das 513 cadeiras na Câmara dos Deputados. Hoje são 
209 representantes da bancada ruralista, aumento esse que a fez superar a bancada evangélica (GUERRA, 2017). Essa bancada é formada por donos de terras, mas também por setores que representam seus interesses.

[...] as prioridades políticas desse grupo de deputados e senadores, envolve a liberação de terras, tanto dos territórios indígenas, quilombolas, como de reservas e parques ecológicos. Também querem flexibilizar leis trabalhistas do setor rural, dar uma nova definição ao "trabalho escravo", mudar as regras para o registro de agrotóxicos e de novos produtos alimentares, alterar a legislação de terras para facilitar a compra por estrangeiros e nas regiões de fronteira, renegociar as dívidas dos ruralistas (TUBINO, 2013).

$\mathrm{O}$ fortalecimento desse segmento garante um avanço nas tentativas de flexibilização das conquistas das populações do campo e no aumento da violência. Dessa maneira, as insuficientes e débeis legislações que prezam pela garantia da regularização fundiária quilombola vêm sendo alvo constante da burguesia rural. Torna-se necessário, assim, lutar pelo patamar civilizatório alcançado e buscar elementos que possam superar a ordem do modo de produção capitalista.

[...] levar as políticas sociais ao limite de cobertura numa agenda de luta dos trabalhadores é tarefa de todos que têm compromissos com a emancipação política e a emancipação humana, tendo em vista elevar o padrão de vida das maiorias e suscitar necessidades mais profundas e radicais. Debater e lutar pela ampliação dos direitos e das políticas sociais é fundamental porque engendra a disputa pelo fundo público, envolve necessidades básicas de milhões de pessoas com impacto real nas suas condições de vida e trabalho e implica um processo de discussão coletiva, socialização da política e organização dos sujeitos políticos. (BEHRING; BOSCHETTI, 2011, p. 190).

Assim, este artigo visa refletir sobre a intensificação dos conflitos socioambientais e sua relação com os processos de demarcação de terras quilombolas no Brasil, na atual conjuntura, marcada pelas inflexões jurídicas e políticas impulsionadoras de maior liberdade para o capital e negadora de direitos aos trabalhadores e às populações tradicionais. 


\section{DESENVOLVIMENTO}

A expansão marítima europeia, que entre outros elementos, resultou na colonização das Américas, tem na expansão da produção e do comércio - e, consequentemente da burguesia - um dos principais impulsos. As transações mercantis que até o século XIV eram basicamente terrestres e de navegação de cabotagem, operam um salto tecnológico com interligação continental, por meio do desenvolvimento das grandes navegações. O início do processo de expansão, no século XV, configura uma mudança radical do desenvolvimento econômico de países como Portugal, Espanha, Inglaterra e Holanda. O objetivo inicial de tal processo era expropriar os novos territórios, entendidos como atrasados e com riquezas naturais abundantes. No entanto, a colonização nas Américas apresentava elementos distintos de outros territórios, como a Índia e a África: o povoamento que até então não era visto como necessário passou a sê-lo, na medida em que possibilitaria produzir e exportar aos países europeus.

Para os fins mercantis que se tinham em vista, a ocupação não se podia fazer como nas simples feitorias, com um reduzido pessoal incumbido apenas do negócio, sua administração e defesa armada; era preciso ampliar essas bases, criar um povoamento capaz de abastecer e manter as feitorias que se fundassem e organizar a produção dos gêneros que interessassem ao seu comércio. A ideia de povoar surge daí, e só daí. (PRADO JÚNIOR, 1994, p. 24).

Assim, a partir do povoamento, o desenvolvimento das atividades econômicas nas Américas consistiu em garantir seu caráter comercial através da expropriação dos produtos naturais e da produção em larga escala de elementos comercializáveis na Europa, utilizando para isso o trabalho forçado de populações indígenas e africanas. E a esse elemento que Prado Júnior (1994) atribui o sentido da colonização.

Esse processo violento ${ }^{2}$ de expropriação de recursos naturais e de populações nativas tinha como objetivo fundamental abastecer o mercado europeu e, em conjunção com outros fatores, acabou por favorecer o processo de acumulação primitiva de capital na Europa. Dessa forma, foi possível garantir a transição do modo de produção feudal para o capitalista. Igualmente, a colonização colaborou para a garantia das bases materiais da Revolução Industrial.

A descoberta das terras auríferas e argentíferas na América, o extermínio, a escravização e o soterramento da população nativa nas 
minas, o começo da conquista e saqueio das Índias Orientais, a transformação da África numa reserva para a caça comercial de peles-negras caracterizam a aurora da era capitalista. Esses processos idílicos constituem momentos fundamentais da acumulação primitiva. A eles se segue imediatamente a guerra comercial entre as nações europeias, tendo o globo terrestre como palco. (MARX, 2013, p. 821).

Com o processo de povoamento e a instalação da grande propriedade monocultura, tornou-se necessária a utilização de uma vasta mão de obra capaz de realizar o trabalho em grande escala para a exportação de materiais que não eram possíveis de serem fabricados na Europa. Para que esse objetivo fosse alcançado utilizou-se o trabalho escravo.

Isso se deu por alguns fatores. Com relação a Portugal, além de não ter contingente populacional suficiente para realizar essa atividade, os colonizadores, de maneira geral, não tinham o objetivo de emigrar para realizar trabalho nas lavouras ou na extração de recursos naturais. Assim, inicialmente os indígenas nativos foram forçados a realizar o trabalho escravo. No entanto, além de conseguir lucro com o próprio processo de escravidão, a possibilidade do tráfico fez com que os portugueses optassem por tornar prevalente a mão de obra escrava africana, que perdurou até o século XIX. Dessa forma, não se priorizou a escravidão negra apenas pelo processo de produção, mas também, porque ela se configurava enquanto um grande comércio pela via de transformação do escravo em mercadoria. Esse movimento só foi possível com o salto tecnológico relativo às grandes navegações que, inclusive, eram de domínio majoritário de Portugal. "É esta exigência da colonização dos trópicos americanos que explica o renascimento da escravidão na civilização ocidental em declínio desde os fins do Império Romano, e já quase extinta de todo neste século XVI em que se inicia aquela colonização". (PRADO JÚNIOR, 1994, p. 122).

Diante do exposto, compreende-se que a escravidão foi um elemento essencial para o processo colonizador nas Américas e em particular no Brasil. Teve dimensões importantes e presença, em praticamente todo o território nacional, existindo de maneira mais contundente nas regiões coloniais de maior exploração e necessidade de mão de obra. Desses escravos, a maior parte, pelos motivos acima apresentados, era formada por negros trazidos forçadamente. 
Assim, é possível aferir que a escravidão brasileira foi uma escravidão negra.

A característica fundamental de ser escravo residia em ser propriedade de outra pessoa. Dessa forma, a sujeição pessoal era o elemento essencial da escravidão, seguida da perpetuidade e da hereditariedade. Ser escravo significava, assim, ser propriedade de outra pessoa, ter sua vontade sujeita a autoridade de seu dono e seu trabalho ser obtido através da força. O escravo entendido enquanto coisa, objeto de trabalho, era similar aos olhos dos senhores como um animal de trabalho. (GORENDER, 2016b).

Para romper com esse processo de coisificação ${ }^{3}$ do escravo, o resgate de sua humanidade era fundamental. Gorender (2016b, p. 94) refere que "O primeiro ato humano do escravo é o crime, desde o atentado contra o senhor à fuga do cativeiro", assim como o processo de repelir o trabalho também se configurava como uma possibilidade de reagir à coisificação à qual estava submetido. "O escravo é inimigo visceral do trabalho, uma vez que neste se manifesta totalmente sua condição unilateral de coisa apropriada, de instrumento animado. A reação ao trabalho é a reação da humanidade do escravo à coisificação". (GORENDER, 2016b, p. 99).

Gorender (2016b) refere que a repulsa do escravo ao trabalho em alguns momentos se estendia ao liberto, gerando um desprezo pela atividade produtiva e uma supervalorização do ócio. Esse elemento, no entanto, não se confirmava nos agrupamentos de negros fugidos, como no Quilombo de Palmares, por exemplo. Lá as atividades produtivas eram realizadas por todos, por serem necessárias à vida coletiva, rompendo assim, com o seu processo alienante.

O trabalho escravo requeria muitos gastos e era empregado em maior quantidade em atividades produtivas fundamentais para a vida na colônia. Dessa maneira, a escravidão se deu de forma predominante no espaço agrário, sendo o escravo rural, elemento essencial na vida econômica colonial. Existiam ainda os escravos de ganho, que viviam nas cidades e através do trabalho realizado entregavam uma parte ao senhor e o resto era para sua própria subsistência. E os escravos domésticos que realizavam serviços pessoais às famílias dos senhores, tanto nas áreas urbanas como rurais. (GORENDER, 2016b). 
Para a existência de tal atividade, uma rede mercantil se formou e incluía desde o tráfico de escravos, os mercados públicos para vendas coletivas, até as vendas privadas de pessoas escravizadas. $\mathrm{O}$ processo de escravização se estendia também aos libertos que, apesar de não serem mais forçados ao trabalho, eram considerados em uma condição especial, inferior aos homens nascidos livres. (GORENDER, 2016b).

Grande parte dos escravos desembarcados no continente americano veio para o Brasil. Das estimativas de 9.500 .000 negros importados $40 \%$ foi destinado ao país, enquanto que nos Estados Unidos esse percentual foi de 6\%, em toda América espanhola 18\%, no Caribe inglês $17 \%$ e no Caribe francês também 17\%. (MOURA, 1993).

No Brasil, os escravos foram distribuídos de acordo com as necessidades econômicas coloniais e ao processo de subordinação dos interesses externos. O quadro abaixo evidencia os principais destinos e atividades desenvolvidas pelos escravos importados ${ }^{4}$.

Quadro 1 - Principais destinos e atividades desenvolvidas pelos escravos

\begin{tabular}{|l|l|}
\hline \multicolumn{1}{|c|}{ Localidade } & \multicolumn{1}{|c|}{ Atividades desenvolvidas } \\
\hline Bahia (com irradiação para Sergipe) & $\begin{array}{l}\text { Campos e plantações de cana-de-açúcar, de } \\
\text { fumo e cacau, serviços domésticos e urbanos e } \\
\text { posteriormente para serviços de mineração na } \\
\text { zona diamantina. }\end{array}$ \\
\hline Rio de Janeiro e São Paulo & $\begin{array}{l}\text { Fazendas açucareiras e cafeeiras da Baixada } \\
\text { Fluminense e para os serviços urbanos. }\end{array}$ \\
\hline Pernambuco, Alagoas e Paraíba & $\begin{array}{l}\text { Plantações de cana-de-açúcar e algodão do } \\
\text { Nordeste. }\end{array}$ \\
\hline Maranhão (irradiando para o Pará) & Cultura do algodão. \\
\hline $\begin{array}{l}\text { Minas Gerais (Irradiando para o Mato } \\
\text { Grosso e para Goiás) }\end{array}$ & Mineração no século XVIII. \\
\hline
\end{tabular}

Fonte: Elaboração própria a partir de: MOURA, C. Quilombos: Resistência ao Escravismo. 3 ed. São Paulo: Editora Ática, 1993.

A escravidão constituiu, assim, forma predominante de trabalho no Brasil colonial e os escravos eram fortemente oprimidos por essa organização do trabalho. Seus mecanismos de resistência aos senhores, aos castigos e à dominação à qual estavam submetidos eram necessariamente um enfrentamento à sua classe antagônica, representada pelos senhores de escravos. No entanto, a degradação 
imposta pela escravidão reverberava sobre os escravos, os seres humanos oprimidos "[...] pelo mais duro dos regimes de exploração do trabalho". (GORENDER, 2016a, p.140).

Nos nossos dias existe a visão romântica do operário predestinado ao papel de herói revolucionário [...]. Visão ingênua que ignora o quanto custa a um operário resistir à degradação cotidiana no mundo da exploração burguesa. Não são poucos os que, em alguma circunstância, cedem a esta degradação. Se os operários de hoje não estão, todos e cada um deles, predestinados a heróis, o mesmo cabe dizer, retroativamente, dos escravos. (GORENDER, 2016a, p. 141).

Muitos elementos dificultavam a formação de uma consciência de classe entre os escravos, inclusive a introdução continuada de africanos, o que potencializava as diferenças étnicas, religiosas e linguísticas. Além disso, a impossibilidade de compartilhamento de experiências sobre os levantes e rebeliões já ocorridos também era um grande obstáculo. "Uma classe não desenvolve sua consciência social senão pela experiência acumulada, e a acumulação das experiências era um processo mais penoso para os escravos do que para outras classes oprimidas". (GORENDER, 2016a, p. 142).

Apesar disso, muitos mecanismos foram utilizados pelos escravos enquanto possibilidades de enfrentamento à opressão escravista. No âmbito individual os suicídios, fugas, agressões, atentados aos senhores e o corpo mole para o trabalho. Este último, além de resistência era também uma técnica que poupava energia dos escravos, imprescindível para sua sobrevivência física. "Eventuais chibatadas danificavam menos do que a exaustão nas longas jornadas de atividade compulsória”. (GORENDER, 2016a, p. 141).

Em termos coletivos outros elementos se configuravam enquanto possibilidades de resistência. Culturalmente foram criadas diferenciações importantes com a cultura europeia e branca, através da religiosidade, cancioneiros, danças ou lendas. Além disso, na colônia muitas foram as conspirações, levantes e formação de quilombos.

O quilombo, segundo Moura (1993), foi a unidade básica de resistência do escravo e teve sua presença em todo o território nacional. Conforme a escravidão se alastrava pelo Brasil, a formação de quilombos também crescia. Os quilombos aglutinavam escravos fugidos, mas também, diversos outros segmentos descontentes com 
a colonização, como desertores do serviço militar, criminosos, indígenas e negros marginalizados. Organizavam-se enquanto polo defensivo, mas mantinham contato com segmentos pobres do sistema colonial, que se refugiavam nos quilombos ou que comercializavam com eles. (MOURA, 1981).

O quilombo, como vemos, nada tinha de semelhante a um quisto, ou grupo fechado, mas, pelo contrário, constituía-se em polo de resistência que fazia convergir para o seu centro diversos níveis de descontentamento e opressão de uma sociedade que tinha como forma de trabalho fundamental a escravidão. (MOURA, 1981, p. $31)$.

Os quilombos além das trocas com grupos marginalizados tinham uma economia policultora, distributiva e comunitária, o que garantia sua permanência e resistência nos territórios. Desenvolviam, entre outras coisas, metalurgia, tecelagem e produção de alimentos. Com essa organização era possível sobreviver, inclusive nos momentos de ataque dos senhores. A manutenção dos quilombos se dava, por um lado, pela organização econômica e pelas atividades produtivas e, por outro. pela defesa constante do território, na tentativa de manter suas dimensões. (MOURA, 1993).

Moura (1993), ao citar Décio Freitas, categoriza 7 tipos diferentes de quilombos que existiram simultaneamente no Brasil, de acordo com as atividades desenvolvidas por eles (Quadro 2).

Quadro 2 - Tipos de quilombos e atividades econômicas desenvolvidas

\begin{tabular}{|l|l|}
\hline \multicolumn{1}{|c|}{ Tipos de quilombo } & \multicolumn{1}{c|}{ Localidade/ Atividades } \\
\hline Agrícolas & Prevaleceram em todas as partes do Brasil. \\
\hline Extrativistas & Prevalência na Amazônia. Viviam da extração das drogas do sertão. \\
\hline Mercantis & $\begin{array}{l}\text { Prevalentes na Amazônia. Adquiriam as drogas do sertão diretamente } \\
\text { com os indígenas e as comercializavam. }\end{array}$ \\
\hline Mineradores & $\begin{array}{l}\text { Prevalentes em Minas Gerais, Bahia, Goiás e Mato Grosso. Viviam da } \\
\text { exploração das minas. }\end{array}$ \\
\hline Pastoris & $\begin{array}{l}\text { Prevalentes no Rio Grande do Sul. Realizavam a criação de gado em } \\
\text { áreas ainda não apropriadas. }\end{array}$ \\
\hline Serviços & $\begin{array}{l}\text { Prevalentes próximo aos centros urbanos onde desenvolviam } \\
\text { atividades remuneradas e retornavam aos quilombos. }\end{array}$ \\
\hline Predatórios & $\begin{array}{l}\text { Existiam por todo o território nacional e viviam dos saques praticados } \\
\text { contra os brancos. }\end{array}$ \\
\hline
\end{tabular}

Fonte: Elaboração própria a partir de Moura (1993)5. 
As pressões crescentes dos escravos, a contínua formação dos quilombos e os ataques aos senhores, somados à Revolução Negra Haitiana (1804), fizeram aumentar o medo com relação a um possível levante negro com as mesmas proporções no Brasil. Além disso, nas regiões de fronteiras existiam trocas de informações sobre o fim dos regimes escravistas como na Argentina e nas Guianas. Dessa forma, houve acréscimo no aparato repressor, tentativas de desorganizar os quilombos e sufocamento das lutas. (GORENDER, 2016a).

Mas, se os escravos brasileiros não conseguiram impor uma perspectiva revolucionária em seus atos, suas ações constantes durante o todo o período colonial colaboraram com o desgaste da prática escravista de trabalho, assim como também, com o processo abolicionista do país.

Além disso, os quilombos ultrapassaram os marcos da escravidão. As populações quilombolas hoje são em sua maioria rurais; apresentam como atividades produtivas, majoritariamente, a agricultura e a criação de animais de pequeno porte. Alguns poucos territórios quilombolas, no entanto, se localizam em áreas urbanas, e apresentam outras relações com a terra e a produção.

As diversas disputas pelo reconhecimento dos territórios quilombolas, apesar das legislações que garantem a regularização fundiária dessa população, agravam a situação em que vivem essas comunidades. Muitas apresentam dificuldades em manter as atividades produtivas da agricultura e o beneficiamento do que é produzido, além das constantes ameaças e cerceamentos de seus territórios.

Assim como os quilombos originários, os contemporâneos não apresentam, de maneira geral e explícita, um potencial por si só revolucionário ${ }^{6}$. No entanto, se configuram enquanto elemento de enfrentamento, consciente ou não, ao desmatamento, à produção mecanizada e ao uso intensivo de veneno, apesar de todas as contradições ${ }^{7}$. E é por isso, que a esses povos são destinados expressões de violência que, em última instância, possibilitam seu extermínio, seja através de medidas institucionais para limitar seu acesso à terra, seja com o aumento vertiginoso da violência no campo ${ }^{8}$.

Em contraponto, após a Segunda Guerra as indústrias bélicas pressionaram o mercado global para a absorção de tecnologias utilizadas no conflito bélico (máquinas e substâncias químicas), até então utilizadas nos confrontos entre as nações. A chamada Revolução 
Verde operou um movimento de destinar veneno (agrotóxicos) para o uso irrestrito na agricultura mundial e, de maneira prevalente, nos países periféricos. Essa movimentação se legitimou com o discurso de combate à pobreza no Sul global ao passo em que modificações operavam na divisão internacional do trabalho, destinando a esses países o papel de produtores de commodities agrícolas e minerais (RIGOTTO; AGUIAR, 2015). A Revolução Verde e a modernização agrícola

[...] preconizam a expansão das agroindústrias, com a utilização intensiva de sementes híbridas e transgênicas, além de insumos industriais (fertilizantes e agrotóxicos), mecanização da produção, uso extensivo de tecnologia no plantio, na irrigação e na colheita, assim como no gerenciamento, sob o argumento legitimador de elevar a produtividade para atender à demanda de alimentos com o intuito de combater a fome (RIGOTTO; AGUIAR, 2015, p. 225).

Essa perspectiva preconizada, no entanto, se comprovou falaciosa. As produções do agronegócio são pautadas no monocultivo e direcionadas ao mercado externo. Dessa forma, permanecem sendo as populações campesinas que garantem o abastecimento do mercado interno de alimentos nos seus países ${ }^{9}$. Além disso, as grandes corporações transnacionais vêm promovendo um novo arranjo da produção mundial e criando formas de submeter os Estados dos países periféricos e suas populações a processos de "[...] flexibilização e desregulamentação de direitos fundiários, ambientais e trabalhistas" (RIGOTTO; AGUIAR, 2015, p. 226).

Esse processo de modernização do campo, pautado no avanço tecnológico possibilitado com a Revolução Verde, foi efetivado no Brasil a partir do II Plano Nacional de Desenvolvimento na década de 1970, situado no contexto da ditadura empresarial e militar. Através dele buscou-se "[...] ampliar a oferta de maquinário e insumos básicos à agricultura". (FARIAS, 2014, p. 30). No entanto, esse processo fortaleceu a concentração de terras, o uso excessivo de pesticidas e a mecanização do campo, fator que garantiu empregos cada vez mais precarizados aos trabalhadores.

Com a redemocratização do país, esse processo foi intensificado a partir do desenvolvimento do agronegócio, configurado através dos pacotes tecnológicos usados em larga escala, ocasionando uma maior concentração e centralização de capitais, mais degradação ambiental e intensificação das contradições sociais. (MARQUES, 2015). 
Desde os anos de 1990, com o processo de desindustrialização do país, provocado pela onda neoliberal, o Brasil promoveu uma inflexão na base de sua economia, passando a investir mais diretamente na produção e comercialização de commodities do setor do agronegócio como possibilidade de obter superávits na balança comercial. Nos governos petistas esse processo recebeu incentivo através de projetos de infraestrutura, relacionados aos transportes, energia e comunicações, com vistas a facilitar e baratear os custos do setor. Esse movimento foi direcionado, principalmente, ao mercado asiático. A expansão econômica na China, Índia e diversos países da região impulsionaram a ida de capitais ao campo, como, por exemplo, os investimentos direcionados ao extrativismo e à produção de alimentos, aumentando a pressão sobre os pequenos produtores rurais, dentre os quais se encontram as comunidades quilombolas. Essa disputa direcionada à propriedade da terra também envolve o uso recursos naturais dos territórios ${ }^{10}$.

Assim, enquanto o latifúndio e o agronegócio direcionam a apropriação individual e privada da terra, entendendo-a enquanto um mero produto com abertura, inclusive, para o capital internacional, os povos tradicionais, incluindo os quilombolas, entendem a terra enquanto bem natural, de uso comunitário, para a produção de alimentos que, em grande parte, são direcionados ao próprio consumo nas comunidades, mas também, para o abastecimento interno de alimentos no país.

As populações quilombolas, através de uma prática produtiva menos predatória com o ambiente natural, evidenciada através de práticas de cultivo e produção, garantem que a atividade produtiva e o uso dos recursos naturais ocorra de modo mais integrado aos ciclos da natureza. Desse modo, a diversificação da produção possibilita um uso menos intensivo do solo, favorecendo, por sua vez, a conservação da biodiversidade. Essas populações garantem, assim, a reprodução das sementes crioulas e prezam pela autonomia do agricultor. Os elementos acima citados são pautados nos princípios agroecológicos. Nesse sentido, a utilização dos recursos naturais não se configura de forma predatória e também não causa desequilíbrios ao ecossistema. (ALTIERI, 2006).

No entanto, para naturalizar a utilização do uso irrestrito dos agrotóxicos, muitas foram as formas utilizadas pelas indústrias químicas e bélicas. Campanhas foram organizadas a partir de instâncias 
governamentais, midiáticas, políticas e sociais, criando uma pretensa necessidade do uso de agrotóxicos e químicos, em geral, para o controle de pragas. $\mathrm{O}$ argumento do combate à fome fez-se crucial para a formação de consensos em torno do monocultivo e da incorporação de técnicas agressivas ao ambiente físico natural e à saúde humana.

Além disso, destaque-se o discurso que afirma a associação entre atraso e pobreza rural, dualidade essa que seria sanada com a incorporação do desenvolvimento tecnológico. Essas estratégias incidiram também sobre os pequenos produtores, incluindo-se, assim, as populações quilombolas, que até então faziam pouco uso desses recursos. Essa movimentação se evidencia seja através de incentivos econômicos para ampliação da produção de base monocultora, seja através da desconstrução do modo de vida e de produção dos pequenos agricultores, dimensionada em um discurso que apresentava o agronegócio como sinônimo de progresso. Os elementos nocivos da utilização desses recursos tecnológicos foram camuflados. Seus reflexos na saúde da população ou no meio ambiente, assim como o seu caráter autoritário, posto que serviçal ao grande capital transnacional em sua relação estreita com a grande propriedade, foram obscurecidos.

[...] diversos programas governamentais de incentivo à agricultura, em pequena e grande escala, estavam diretamente atrelados à obrigatoriedade no uso dos produtos químicos (fertilizantes e agrotóxi$\cos$ ), os quais exigiam inclusive que os pequenos agricultores adotassem essas práticas, muitas vezes destoantes de seus modos de vida e trabalho tradicionais. (RIGOTTO; AGUIAR, 2015, p. 228).

Por esse antagonismo entre as perspectivas do agronegócio e seus representantes e os povos tradicionais e quilombolas, são desenvolvidos inúmeros conflitos. Essas populações, por exemplo, integram territórios cada vez mais transformados em objeto de cobiça do capital e do seu avanço no campo. Os interesses desses segmentos de classe são, dessa maneira, inconciliáveis, o que acaba por gerar conflitos de grande magnitude e de dimensões nacionais.

O mapa a seguir, retirado do site que mapeia os conflitos socioambientais no Brasil, organizado pela Fiocruz, dimensiona a expansão dos conflitos envolvendo povos quilombolas no Brasil. De acordo com o mapa, em praticamente todos os estados da federação 
existem registros de conflitos com populações quilombolas em andamento, como pode ser visualizado abaixo.

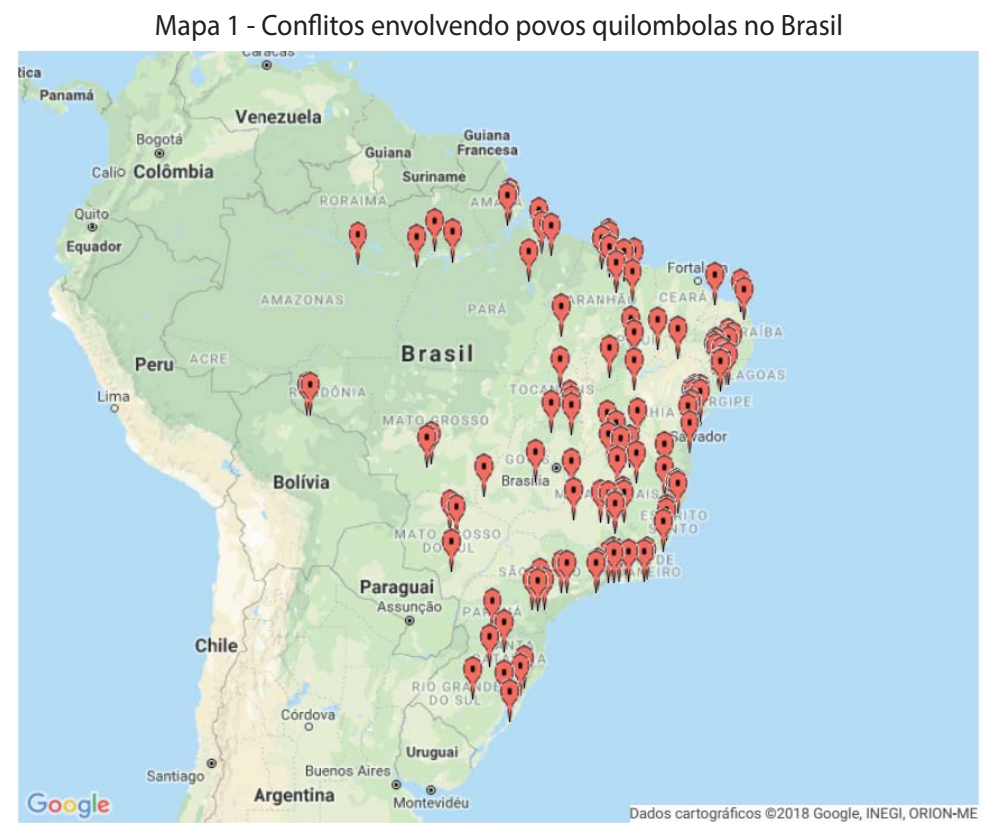

Fonte: FUNDAÇÃO OSWALDO CRUZ. Mapa de Conflitos Envolvendo Injustiça Ambiental e Saúde no Brasil. Rio de Janeiro, [20--?]. Disponível em:<https://www.conflitoambiental.icict.fiocruz.br/ index.php>. Acesso em: 12 mar. 2018.

Existem diversas causas para a existência desses conflitos, mas, a maior parte das lideranças comunitárias quilombolas apontam que todos se intensificam, principalmente, em decorrência da morosidade dos processos de demarcação e garantia dos territórios. Hoje existem 2547 comunidades certificadas pela Fundação Cultural Palmares (FCP, 2017) enquanto comunidades quilombolas; no entanto, segundo a Coordenação Nacional de Articulação das Comunidades Negras Rurais Quilombolas (CONAQ) existem mais de 5000 comunidades quilombolas espalhadas pelo país.

Além disso, das comunidades certificadas pela FCP atualmente, apenas 220 terras foram tituladas pelo Instituto Nacional de Colonização e Reforma Agrária (INCRA) (2017), órgão oficial responsável por essa etapa da demarcação, beneficiando, assim, apenas 152 territórios e 294 comunidades. São 1536 processos em andamento 
no órgão, como apresentado no quadro abaixo, sendo o Nordeste a região onde existe o maior número de processos em andamento.

Tabela 1 - Processos de demarcação de terras quilombolas em andamento no INCRA

\begin{tabular}{|l|l|}
\hline \multicolumn{1}{|c|}{ Região } & \multicolumn{1}{c|}{ Total de processos em andamento } \\
\hline Norte & 130 \\
\hline Nordeste & 872 \\
\hline Sudeste & 279 \\
\hline Sul & 143 \\
\hline Centro-oeste & 112 \\
\hline
\end{tabular}

Fonte: Elaboração própria a partir de INCRA.

Esses conflitos produzem impactos diretos para as populações quilombolas. $\mathrm{O}$ aumento vertiginoso da violência no campo e as frequentes tentativas de flexibilização das legislações que regulamentam os processos de demarcação de terras dessa população são alguns dos exemplos.

De 1990 até hoje, o ano de 2003 foi o mais violento para a população do campo no Brasil; houve 73 assassinatos. De 2004 até 2014 o número de mortes não ultrapassou 39 casos. Mas, em 2015 a quantidade de assassinatos voltou a subir. No ano em questão 50 pessoas foram mortas e em 2016 foram 61 camponeses assassinados. (COORDENAÇÃO NACIONAL DE ARTICULAÇÃO DAS COMUNIDADES NEGRAS RURAIS QUILOMBOLAS, 2017).

De acordo com os dados parciais divulgados pela Comissão Pastoral da Terra (CPT), no ano de 2017 foram assassinadas 65 pessoas em conflitos no campo no Brasil. A quantidade de assassinatos confere ao país o título de mais violento para populações campesinas no mundo. Além disso, houve uma mudança com relação à generalização da violência, pois muitos desses assassinatos ocorreram de forma coletiva, através das chacinas. Em um deles 6 quilombolas foram assassinados na comunidade Iúna, em Lençóis, Bahia ${ }^{11}$. (COMISSÃO PASTORAL DA TERRA, 2018).

De acordo com os dados divulgados pela CONAQ, o ano de 2017 foi o mais violento para as populações quilombolas na última década; até o momento 14 mortes foram confirmadas. Apesar de os órgãos oficiais relatarem que as mortes não foram ocasionadas por motivações políticas e pelos conflitos pela terra, das pessoas assassinadas 6 eram lideranças comunitárias. Ainda segundo a CONAQ (2017), entre 2011 e 2015 foram assassinados 2 quilombolas; em 
2016 esse número subiu para 8 casos, o que denota uma tendência de crescimento.

As pressões para a flexibilização de legislações que garantem o acesso, uso e posse das terras quilombolas também vêm se intensificando. Em 2017 foi retomado o julgamento da Ação Direta de Inconstitucionalidade (ADI - 3239) no Supremo Tribunal Federal (STF).

A mencionada Ação foi aberta pelo antigo Partido da Frente Liberal (PFL), hoje Democratas, logo após a publicação do Decreto 4887/2003 que institucionaliza a regularização fundiária quilombola. Com essa ação, o antigo PFL pretendia alegar a inconstitucionalidade do decreto, questionando inclusive o critério de autoatribuição, elemento presente na Convenção $\mathrm{N}^{\circ} 169$ da OIT da qual o Brasil é signatário. O STF, no dia 8 de fevereiro de 2018, no entanto, votou majoritariamente contra a proposta da ADI 3239, inclusive sem a aplicação da tese do marco temporal. A proposta dessa tese é de que apenas poderiam ser demarcadas as terras que estivessem efetivamente ocupadas pelos quilombolas na data de 5 de outubro de 1988 . Essa proposta dificultaria o acesso efetivo das comunidades aos seus territórios.

Essa vitória do movimento quilombola nacional não se deu sem pressão popular. Foi através da articulação de diversos movimentos sociais e uma ampla campanha encabeçada pela CONAQ em todo o Brasil, envolvendo intelectuais, personalidades do meio artístico-cultural, religiosos, etc. que o movimento quilombola pôde assegurar a manutenção dessa conquista.

O movimento quilombola conseguiu, assim, apesar de todas as limitações conjunturais, angariar diversos simpatizantes no conjunto da classe trabalhadora e também em segmentos dessa classe. Esse fator evidencia que a questão quilombola vem conseguindo respaldo e legitimidade para muito além dos efetivos quilombolas.

A manutenção do decreto de regularização fundiária não afasta, no entanto, por completo, a possibilidade de flexibilizações tanto em relação ao processo de demarcação de terras, quanto na sua viabilidade. Os recursos destinados à demarcação de terras, por exemplo, foram reduzidos. Comparando com o montante destinado no ano de 2015, a redução foi de 60\% em 2017. Também em 2017 
vários foram os cortes em programas sociais direcionados aos camponeses.

[...] Os recursos para a Assistência Técnica e Extensão Rural (ATER), de igual modo, foram somente metade do valor destinado no ano de 2016. O Programa de Aquisição de Alimentos (PAA) também sofreu cortes que chegam a inviabilizá-lo em vários estados. Em 2016, foram destinados ao Programa R \$ 439 milhões. Já em 2017 foram somente R\$ 150 milhões, o que representou uma redução de $66 \%$ em um único ano. A soma dessas iniciativas permitirá que assentamentos que nunca receberam qualquer infraestrutura possam ter seus lotes negociados, deixando as famílias presas fáceis do assédio dos latifundiários. (COMISSÃO PASTORAL DA TERRA, 2018).

Entretanto, em 2018 a situação tende a se intensificar; até agora houve também a redução em $35 \%$ dos recursos para a agricultura familiar e um corte de mais de $56 \%$ de recursos destinados à segurança alimentar e nutricional. Além disso, existe a previsão de tramitação de dois projetos de lei que articulam interesses da bancada ruralista. O primeiro diz respeito à possibilidade de compra ou arrendamento de terras por estrangeiros, projeto que vem sendo conduzido diretamente pela Casa Civil. O outro diz respeito ao repasse para grandes empresas do controle exclusivo sobre o uso de sementes, mudas e plantas modificadas. (COMISSÃO PASTORAL DA TERRA, 2018).

Dessa forma, a comercialização do produto que for obtido na colheita dependerá da autorização do detentor das chamadas cultivares, que são plantas que tiveram alguma modificação pela ação humana, como as híbridas, por exemplo. Considerando o aumento exponencial do cultivo de sementes híbridas e transgênicas produzidas por grandes corporações estrangeiras, que também controlam a produção de agrotóxicos, podemos entender os impactos integrados que essas medidas, se aprovadas, poderão provocar na produção de comida no Brasil. (COMISSÃO PASTORAL DA TERRA, 2018).

Nos termos acima referidos, tomamos como suposto que a luta dos povos quilombolas apresenta elementos classistas e possibilita que exista uma abertura contraditória para a defesa de seus interesses a partir do movimento das classes sociais e seus segmentos. 


\section{CONCLUSÃO}

Os investimentos e incentivos do Estado brasileiro ao agronegócio evidenciam o modelo de campo que vem sendo construído no país em concordância com o mercado mundial. É com a produção cada vez mais mecanizada, com utilização excessiva de pesticidas e adubos químicos que cresce o monocultivo. A maior parte dos investimentos no campo brasileiro são para fortalecer esse modelo, sabidamente destrutivo e degradante, tanto para a natureza, como para a população que trabalha em seus espaços.

Assim, aos povos que resistem no campo, cuja forma de produzir e de se relacionar com o ambiente natural não é pautada nos mesmos elementos que a indústria rural, sobra a dificuldade de garantir e preservar seus territórios.

Os conflitos socioambientais tão presentes na dinâmica das populações quilombolas revelam o caráter esmagador do latifúndio e do agronegócio. A ofensiva destes últimos, amparada no Estado brasileiro, visa em última instância exterminar essas populações, seja através da violência propriamente dita e da tendência ao aumento dos assassinatos no campo, seja nos processos de flexibilização legal.

Contudo, é com resistência e articulação, herdadas das lutas de seus antepassados e ancoradas na atual realidade brasileira, que essas comunidades sobrevivem. Muitas são as contradições desse processo que destinam a essas populações condições precárias de acesso ao seu território e garantia de seu modo de viver e produzir. No entanto, é através da luta incansável por uma outra sociabilidade na qual a terra possa ser usufruída em sua plenitude e não a serviço dos interesses privados, que essas populações poderão garantir suas particularidades.

\section{REFERÊNCIAS}

ALTIERI, M. Agroecologia: princípios e estratégias para a agricultura sustentável na América Latina do século XXI. In: MOURA, E. G.; AGUIAR, A. das C. F. O desenvolvimento rural como forma de aplicação dos direitos no campo: princípios e tecnologias. São Luís: UEMA, 2006. p. 83-100.

BEHRING, E.; BOSCHETTI, I. Política Social: fundamentos e história. 9. ed. São Paulo: Cortez, 2011. 
COMISSÃO PASTORAL DA TERRA. Balanço da questão agrária brasileira em 2017. Goiânia, 2018. Disponível em: <https://www. cptnacional.org.br/publicacoes-2/destaque/4183-balanco-da-questaoagraria-brasileira-em-2017>. Acesso em: 31 maio 2018.

COORDENAÇÃO NACIONAL DE ARTICULAÇÃO DAS COMUNIDADES NEGRAS RURAIS QUILOMBOLAS. Violência Contra Quilombolas Dispara em 2017. Brasília, DF, 2017. Disponível em: $<$ http://conaq.org.br/noticias/violencia-contra-quilombolasdispara-em-2017/>; Acesso em: 07/03/2018.

FARIAS, L. F. Agronegócio e Luta de Classes: diferente formas de subordinação do trabalho ao capital no complexo citrícola paulista. São Paulo: Editora Sundermann, 2014.

FUNDAÇÃO CULTURAL PALMARES. Comunidades Remanescentes de Quilombos. Brasília, DF, [20--?]. Disponível em: $<$ http://www.palmares.gov.br/comunidades-remanescentes-dequilombos-crqs $>$. Acesso em: 13 mar. 2018.

FUNDAÇÃO OSWALDO CRUZ. Mapa de Conflitos Envolvendo Injustiça Ambiental e Saúde no Brasil. Rio de Janeiro, [20--?]. Disponível em: $<$ https://www.conflitoambiental.icict.fiocruz.br/index. php>. Acesso em: 12 mar. 2018.

GORENDER, J. A Escravidão Reabilitada. 1. ed. São Paulo: Expressão Popular, Perseu Abramo, 2016.a

. O Escravismo Colonial. 6. ed. São Paulo: Expressão Popular, Perseu Abramo, 2016b.

GUERRA, R. Quilombolas: a luta pela direito de existir. Repórter Brasil, São Paulo, 2017. Disponível: <http://reporterbrasil.org. br/2017/08/quilombolas-a-luta-pelo-direito-de-existir/>. Acesso: 7 mar. 2018.

INSTITUTO NACIONAL DE COLONIZAÇÃO E REFORMA AGRÁRIA. Regularização de Território Quilombola: perguntas e respostas. Brasília, DF, 2017. Disponível em: <http://www.incra.gov. $\mathrm{br} / \mathrm{sites} /$ default/files/incra-perguntasrespostas-a4.pdf $>$. Acesso em: 10 mar. 2018.

MAPA Inédito Coloca o Brasil em $3^{\circ}$ Lugar em Conflitos Ambientais. BBC News, [S. 1.], mar. 2014. Disponível em: <http://www.bbc.co.uk/ portuguese/noticias/2014/03/140321_disputas_ambientais_mdb>. Acesso em: 29 set. 2016. 
MARQUES, G. de S. Luta Camponesa e Reforma Agrária no Brasil. São Paulo: Editora Sundermann, 2015.

MARTINS, T. C. S. Questão Étnico-Racial: seus nexos com o Núcleo de Fundamentos da Formação Sócio-Histórica da Sociedade Brasileira. In: GONÇALVES, M. da C. V.; MARTINS, T. C. S.; SANTOS, V. N.. (Org.). Temas Contemporâneos no Serviço Social: um convite à reflexão. São Cristóvão: Editora UFS, 2016. p. 21-48.

MARX, K. O Capital. Crítica da economia política. Livro I. São Paulo: Boitempo, 2013.

MOURA, C. Os quilombos e a rebelião negra. São Paulo: Brasiliense, 1981.

. Quilombos: Resistência ao Escravismo. 3 ed. São Paulo:

Editora Ática, 1993.

PRADO JÚNIOR, C. Formação do Brasil Contemporâneo: colônia. 23. ed. São Paulo: Brasiliense, 1994.

RIGOTTO, R. O Uso Seguro de Agrotóxicos é um Mito. Rio de Janeiro: FIOCRUZ, 2010. Entrevista realizada por Leila Leal. Disponível em:<http://www.epsjv.focruz.br/index.php?Area=Entrevist a\&Num=17\&Destaques $>$. Acesso em: 17 abr. 2018.

; AGUIAR, A. C. P. Modelo produtivo do agronegócio, agrotóxicos e saúde humana. In: MITIDIERO JÚNIOR, M. A.; GARCIA, M. F.; VIANA, P. C. G. (Orgs.). A Questão Agrária no Século XXI: escalas, dinâmicas e conflitos territoriais. São Paulo: Outras Expressões, 2015.

TUBINO, N. Bancada Ruralista: tudo pela terra. Carta Maior, [S. 1.], out. 2013. Disponível em: <http://www.cartamaior.com.br/?/Editoria/ Politica/Bancada-ruralista--tudo-pela-terra/4/29182>. Acesso em: 20 set. 2017.

\section{Notas:}

1 O agronegócio pode ser compreendido enquanto uma fusão entre o latifúndio, a indústria fármaco-química, a biotecnologia, a indústria metal-mecânica e o sistema financeiro garantindo uma expansão conjunta, mesmo com a presença de tensionamentos, sobre o campo (RIGOTTO, 2010).

2 O sistema colonial baseia-se na violência mais brutal [...] A violência é a parteira de toda sociedade velha que está prenhe de uma sociedade nova. Ela mesma é uma potência econômica. (MARX, 2013, p. 821).

3 De acordo com Gorender (2016b) quanto maior o processo mercantil de determinada economia, maior é a tendência em extremar a coisificação do escravo. 
4 Aos estados do sul, especialmente Santa Catarina e Rio Grande do Sul, também foram destinados escravos negros, no entanto, com número reduzido em relação a outras regiões do país. (MOURA, 1993).

5 Nos seis últimos a agricultura não estava ausente, mas desempenhava papel complementar. (MOURA, 1993).

6 No entanto, diversas são as comunidades quilombolas e seus movimentos específicos, que se associam com outros movimentos sociais, do campo e da cidade, cuja pauta muitas vezes ultrapassa as necessidades mais imediatas e apresentam propostas, como estratégia política, de mudanças de sociabilidade.

7 Muitas comunidades quilombolas, em seu processo de cultivo, utilizam pesticidas. No entanto, sua produção é majoritariamente para o consumo e para a garantia de sobrevivência das famílias nas comunidades.

8 De acordo com dados da Comissão Pastoral da Terra (CPT) (2018), em 2017, 65 pessoas foram assassinadas no campo e muitas delas com requintes de crueldade.

9 Cerca de $70 \%$ da população mundial se alimenta do que é produzido por pequenos agricultores. DOLCE, J.

Semana do Meio Ambiente: $70 \%$ dos alimentos são produzidos por pequenos agricultores. Brasil de Fato, jun. 2016. Disponível em: <https://www.brasildefato.com.br/2016/06/01/ semana-do-meio-ambiente-70-dos-alimentos-sao-produzidos-por-pequenosagricultores/>. Acesso em: 23 set. 2017.

${ }^{10}$ Mas, o processo de garantir um acesso restrito à terra é anterior a esse momento. Desde 1850 com a promulgação da Lei de Terras, o Brasil adotou um modelo privatizante para a posse das terras nacionais. Apenas a partir da compra era possível ter acesso a esse bem natural. Essa lei inviabilizou a posse da terra por pequenos produtores, preservando, dessa maneira, as propriedades rurais em poder dos latifundiários.

${ }^{11}$ Sobre o massacre em Iúna mais informações podem ser acessadas no site da CPT (Disponível em: $<$ https://www.cptnacional.org.br/publicacoes/noticias/14-noticias/acoesdos-movimentos/4012-entidades-e-movimentos-discutem-massacre-de-iuna-em-lencoisba-relacao-com-o-trafico-ou-conflito-agrario>). 